\title{
Ecologic and Sociodemographic Risk Determinants for Dengue Transmission in Urban Areas in Thailand
}

\author{
Surachart Koyadun, ${ }^{1,2}$ Piyarat Butraporn, ${ }^{1}$ and Pattamaporn Kittayapong ${ }^{1,2}$ \\ ${ }^{1}$ Center of Excellence for Vectors and Vector-Borne Diseases, Faculty of Science, Mahidol University, \\ Nakhon Pathom 73170, Thailand \\ ${ }^{2}$ Department of Biology, Faculty of Science, Mahidol University, Bangkok 10400, Thailand
}

Correspondence should be addressed to Pattamaporn Kittayapong, pkittayapong@msn.com

Received 17 May 2012; Accepted 15 August 2012

Academic Editor: Jose G. Estrada-Franco

Copyright (๑) 2012 Surachart Koyadun et al. This is an open access article distributed under the Creative Commons Attribution License, which permits unrestricted use, distribution, and reproduction in any medium, provided the original work is properly cited.

\begin{abstract}
This study analyzed the association between household-level ecologic and individual-level sociodemographic determinants and dengue transmission in urban areas of Chachoengsao province, Thailand. The ecologic and sociodemographic variables were examined by univariate analysis and multivariate logistic regression. In the ecologic model, dengue risk was related to households situated in the ecotope of residential mixed with commercial and densely populated urban residential areas (RCDENPURA) $(\mathrm{aOR}=2.23, P=0.009)$, high historical dengue risk area $(\mathrm{aOR}=2.06, P<0.001)$, and presence of household window screens $(\mathrm{aOR}=1.62, P=0.023)$. In the sociodemographic model, the dengue risk was related to householders aged $>45$ years $(\mathrm{aOR}=3.24$, $P=0.003)$, secondary and higher educational degrees $(\mathrm{aOR}=2.33, P=0.013)$, household members $>4$ persons $(\mathrm{aOR}=2.01$, $P=0.02)$, and community effort in environmental management by clean-up campaign $(\mathrm{aOR}=1.91, P=0.035)$. It is possible that the preventive measures were positively correlated with dengue risk because these activities were generally carried out in particular households or communities following dengue experiences or dengue outbreaks. Interestingly, the ecotope of RCDENPURA and high historical dengue risk area appeared to be very good predictors of dengue incidences.
\end{abstract}

\section{Introduction}

Dengue virus, an Aedes mosquito-borne viral pathogen belonging to the family Flaviviridae, is the cause of dengue fever (DF) and dengue hemorrhagic fever (DHF). The emergence and reemergence of DF/DHF have become a significant public health burden in the tropics and subtropics [1-5]. Due to the lack of an effective tetravalent dengue vaccine that can secure lifelong immunization, Aedes mosquito control measures have primarily been employed to prevent disease outbreak and interrupt transmission during the outbreak [6]. Regarded as a reemerging infectious disease $[1,4,5]$, intermittent epidemics of DF and DHF have occurred in vulnerable populations. Such outbreaks reflect the failure of current prevention and control efforts, despite the fact that some successful cases of vector control in the Americas, Cuba, and Singapore had shortened outbreak periods and stopped the diseases from spreading [7-9]. In some cases, an application of appropriate vector control measures along with community participation have proven more effective and sustainable than antimosquito approaches alone [1012].

Several reports have shown a coherent argument that transmission dynamics of dengue viruses result from very complex epidemiology and ecology of the disease. Such dengue transmission dynamics are the interaction among humans, dengue viruses, vectors, and ecosystems, of which biotic and abiotic determinants have both direct and indirect influences on dengue transmission [13-16]. Obviously in some cases, a useful set of environmental and sociodemographic factors, which constituted age-dependent classes, numbers and densities of urban populations, economic classes, and inhabitations, are central components of analysis of temporal and spatial relationships of dengue incidences [17-20]. Also, a vector-based dengue model [21] can predict transmission dynamics, based primarily on the infestation 
and/or reinfestation of domestic and peridomestic Aedes mosquito vectors in human inhabitations. Nonetheless, in different complex epidemiological settings, various factors that can influence dengue transmission dynamics remain to be established. This is because of more diverse sociocultural contexts and changes in sociopolitic, socioeconomic, demographic, technologic, and environmental conditions as well as ineffective management of household-level information and improper implementation of those control strategies.

Investigation into such sociodemographic, environmental perspectives can provide foresight into the appropriateness of dengue control efforts, give answers to unexpected vector control responses, and contribute to effective management solutions in an ever-changing environment. Of note, a plausible paradigm of interdisciplinary approach that integrates the ecologic and sociodemographic dimensions of dengue [22-27] has permitted an analysis of dengue transmission risk to determine what pivotal drivers significantly contribute to dengue transmission in an urban environment. In this regard, we applied two sets of household-level ecologic and individual-level sociodemographic factors to determine whether two fitted models of dengue-related determinants predicted the dengue transmission risk in urban areas of Chachoengsao province, Thailand, known for epidemics of DF/DHF [12]. Ultimately, the findings of this study would benefit better management of effective dengue prevention and control, especially in resourcelimited developing countries.

\section{Materials and Methods}

2.1. Study Area and Household Selection. Chachoengsao province was a representative of geographically defined areas (Figure 1), including small-and medium-sized municipalities as well as four main types of landscapes: mountains, rivers, flatlands, and wetlands. Both urban and semiurban communities are situated in low-lying, generally flat areas surrounded by rice fields and orchards. In the area, the climate is characterized by a long rainy season (JuneOctober), a winter dry season (November-January), and a hot dry season (February-May). Given the complexity of its demographic and socioeconomic dispersions, the province is administratively divided into 11 districts covering a total area of $5,370 \mathrm{~km}^{2}$ with basic infrastructures of connecting roads, electricity, piped water supply system, communication system, and health service system.

Two-stage random sampling was applied for selecting targeted households. The 120 blocks initially assigned to four different districts were used to select 12 blocks (approximately 100 houses each), based on the degree of urbanization and the intensity of dengue transmission (Figure 2). Six urban blocks were selected from the municipality of Muang district and the capital of Chachoengsao province, while the other six semiurban blocks were chosen from three subdistrict municipalities: Bang Pakong, Ban Pho, and Bang Khla. According to this household selection, a sample size was calculated based on $95 \%$ confidence to detect the prevalence of IgG-IgM-positive school children at $19.2 \%$ in
Chachoengsao province [12] with a $3 \%$ of accepted error. The statistically required sample size of 994 was increasing by $20 \%$ to allow for missing data, resulting in 1,200 households, which were derived from the 12 selected blocks. All were subsequently used for household surveys during AugustOctober 2007 to collect household-level and individual-level information with the assistance of interdisciplinary teams (i.e., each team included well-trained professional nurses and/or public health officers), as described below.

The establishment of interdisciplinary approaches and teams was supported by a WHO/TDR/IDRC-funded multicountry study. In this study, the instruments provisionally guided by multicountry supporting teams were initially developed from a series of community of practice workshops delivered through a multicountry network in Asia. The tools were partly modified with the addition of a useful set of variables, which corresponded to sociocultural contexts of Thailand. As technically validated by the authors, all tools included the structured questionnaires on households and individuals along with the environmental observation checklist.

2.2. Ecologic Factors of Households. The structured questionnaires on households along with the environmental observation checklist were used to gather a set of ecological data of the entire 1,200 households. The data included ecotope, dengue risk area, number of house floors, floor of principal living (i.e., homeowners or any member often used a space of everyday family living as principal living area of the first floor or the upper floors), construction material of the house, number of house windows, having window screens, having a yard/open space, having bushes in a yard/open space, main purpose of house, and household attachment (i.e., the attached houses had at least one shared wall, whereas the detached houses had standalone property with no sharing wall). Face-to-face interviews were carried out using the representative respondents who were family members, 18 years of age or older.

In this study, we applied an ecotope concept, which is originally defined as the smallest ecologically-distinct features in a landscape mapping and classification system. As mentioned earlier, those selected 12 blocks were assigned to have 4 different ecotopes (Figure 3), which spanned both urban and semiurban blocks of the study area. The difference is based quantitatively and qualitatively on the distribution of houses, the socioeconomic status (SES) of local inhabitants, infrastructural services, land use, and land type. The commercial ecotope (C) denoted a majority of attached houses with a 0.07 -meter mean distance of nearest houses, a high SES of occupants, and good basic infrastructure, along with a great deal of commercial and business buildings. The ecotope of a densely populated urban residential area (DENPURA) is characterized by most attached houses with a 0.63 -meter mean distance of nearest houses, low SES of the population, and relatively low degree of community development, including social and economic opportunities and access to health care resources as well as infrastructural water supply and waste management and a lack of vegetation and/or 


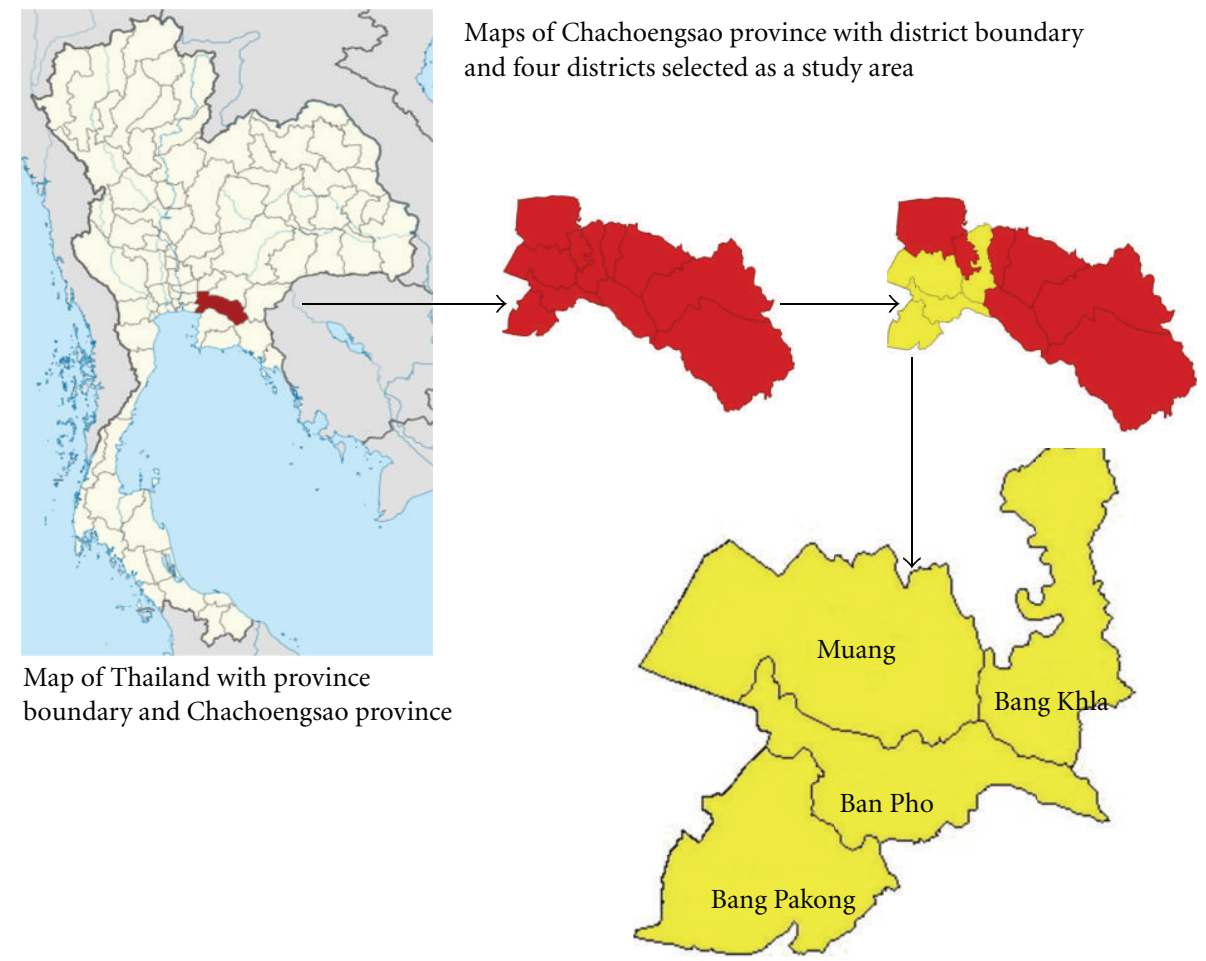

Figure 1: Maps of study area: 4 districts including Muang, Bang Pakong, Ban Pho, and Bang Khla. Map of Thailand obtained from http://www.wikimedia.org/.

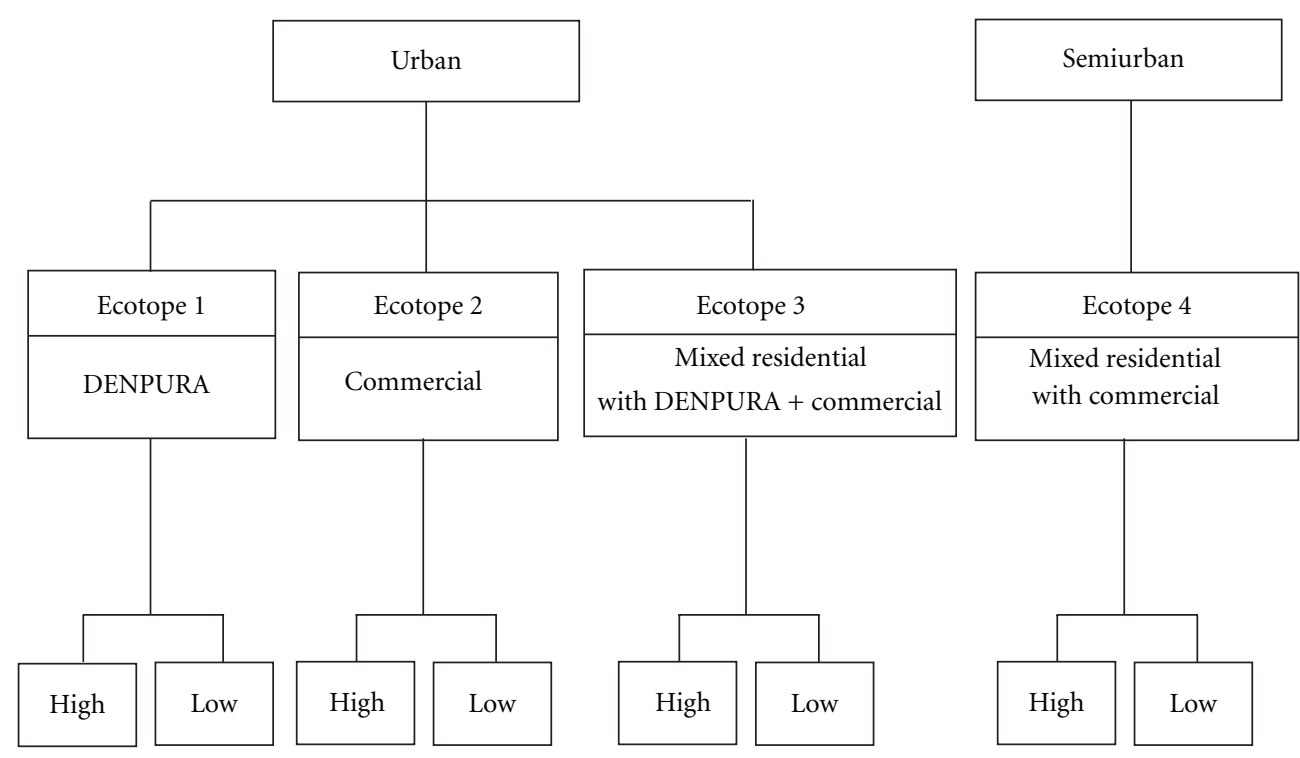

FIgURE 2: Diagram showing selection criteria for the 12 blocks: (1) degree of urbanization and (2) intensity of dengue transmission. Abbreviation: DENPURA—densely populated urban residential area.

forested areas. The ecotope of residential (R) mixed with $\mathrm{C}$ and DENPURA (RCDENPURA) exhibits a main residential zone prominently scattered with C and DENPURA and has a 3.37-meter mean distance of nearest houses, while the residential mixed only with commercial (RC) - signifying an overlap of urban and rural areas-is an area mainly for dwelling but which is also filled in partly with commercial settlements and has a 4.58-meter mean distance of nearest houses. Finally, each ecotope investigated in this study had a different number of study households-C $(n=200)$, DENPURA $(n=200)$, RCDENPURA $(n=200)$, and RC $(n=600)$.

As for the risk area, the classification of historical dengue risk areas (high and low degrees of dengue transmission) 

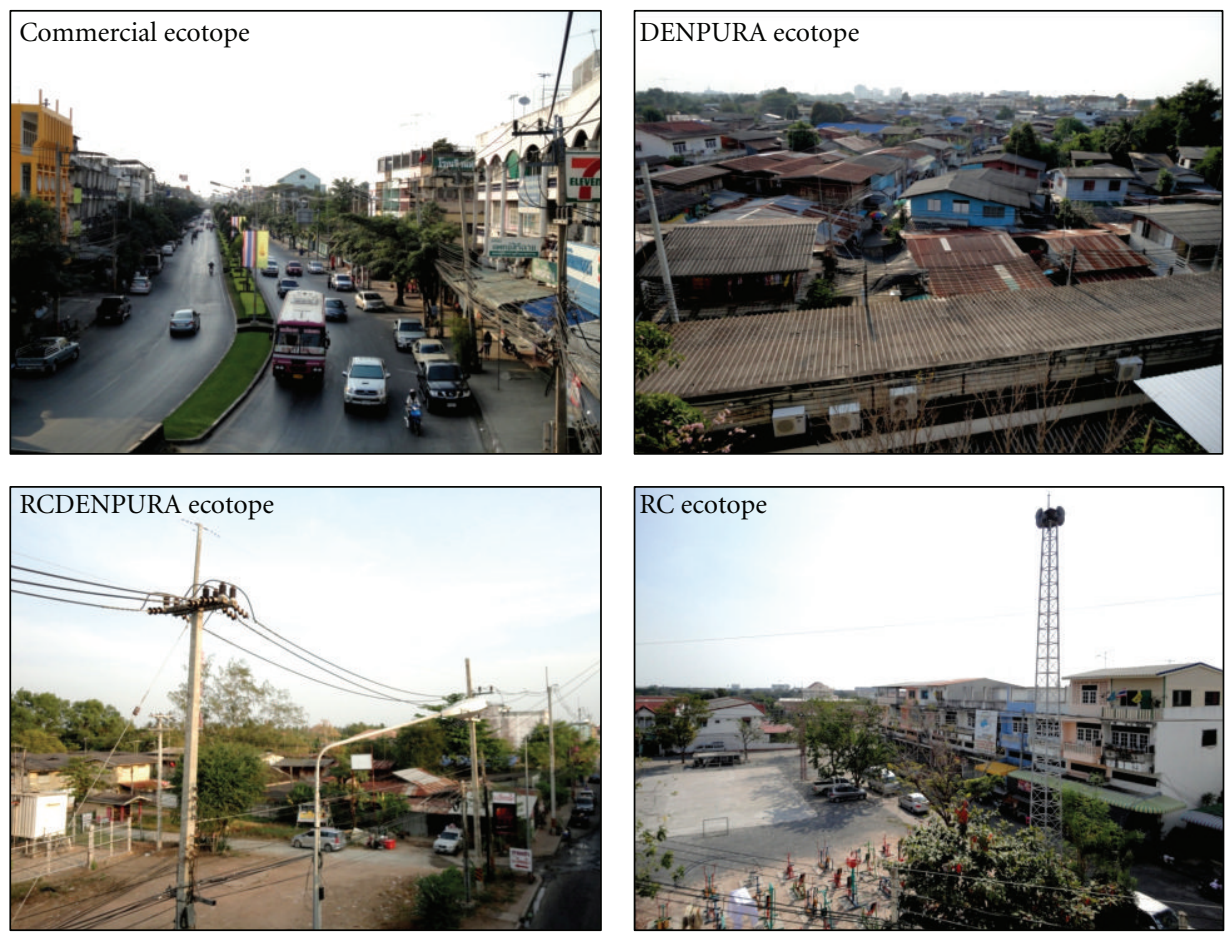

FIGURE 3: The four different characterized ecotopes.

was drawn from which its epidemic pattern that normally occurs on a 2-3 year-cycle transmission [28]. Therefore, based on the past situation of national surveillance of dengue cases, the definition of dengue transmission risk areas relies upon a 3- to 5-year median of dengue cases. In this study, the data of the confirmed dengue cases retrieved from the national epidemiological surveillance system were obtained from the Chachoengsao General Hospital and Chachoengsao Provincial Public Health Office [29]. Therefore, based on the ecotope assignment (Figure 2$)$, the study households $(N=$ 1,200 households) were categorized into 2 historical dengue risk areas: 6 high-transmission blocks ( $n=600$ households) that had the highest 5-year medians of dengue cases and 6 low-transmission blocks ( $n=600$ households) that had the lowest 5-year medians of dengue cases.

2.3. Sociodemographic Factors of Respondents. The structured questionnaires on individuals, which had a significant reliability of knowledge, attitude, and practice (Cronbach's alpha coefficient $=0.7$, were used to gather a set of sociodemographic data using those representative respondents of the entire 1,200 households as previously mentioned. The data included age, education level (highest school degree), occupation, movement during the last 3 months, residence time in house, residence time in neighborhood, number of household members, average family income, knowledge about dengue and its vectors, attitude about dengue vector control in terms of gender, family, and government roles, household water storage (i.e., by using any water-storing containers), household practices to reduce the nuisance of mosquitoes, household practices to prevent Aedes breeding places, last time visited by health personnel, receiving dengue control support/materials, and community efforts in environmental management by clean-up campaign.

Regarding household practices to reduce the nuisance of mosquitoes, questions were asked about household activities which could be categorized into 3 groups: (1) chemical control (e.g., indoor spraying, putting chemicals in water containers and personal protection with repellents), (2) physical control (e.g., removing rubbish, covering water containers and killing mosquitoes), and (3) biological control (e.g., putting fish in water containers). The chemical and physical control activities were ranked based on frequent actions: low (never or either one of three actions) and high (two or more actions), whereas the biological control activity was ranked based on the action "No or did not apply" and "Yes or applied."

The questions of household practices to prevent Aedes breeding places could be categorized into 3 groups: (1) chemical control (e.g., putting chemicals in water containers), (2) physical control (e.g., removing rubbish, covering the water containers, changing water once a week, eliminating stagnant water, brushing/cleaning inner surface of water containers, and removing larvae), and (3) biological control (e.g., putting fish in water containers). The chemical and biological control activities were ranked as either "Yes" or "No." The physical control activities were ranked based on the frequency of actions: low (never, one, or two actions) and high (three and more actions).

All the respondents provided informed consent after they were completely informed about the study's purpose, as well as the advantage and disadvantage of participation. 
The ethical clearance for this study was approved by the Institutional Review Board of Mahidol University.

2.4. Data Analysis. Dengue-related determinants as the outcomes of dengue transmission risk in the study area included the households that had past history of dengue cases and the respondents or householders that had history of dengue infections in their lifetime before the study. Generally speaking, the principal outcome of this study was to identify whether those household-level ecologic and individual-level socioeconomic variables were correlated to these denguerelated determinants. Therefore, in two separate ecological and socioeconomical models, a univariate analysis of the individual explanatory variables was used to analyze the association of the dengue-related determinants using the chi-square test $(P<0.05$ or $P<0.1)$. Then, they were entered into the multivariate logistic models and odds ratios (aORs) adjusted for all of these variables and 95\% confidence intervals (CI) were calculated. In fitted models, a pseudo $R^{2}$ value was considered when the regression model was sufficiently adequate. The likelihood-ratio (LR) test $(P<$ $0.05)$ was used to test the significance of all the related predictors while the Wald's test $(P<0.05)$ was used to test the statistical significance of each coefficient $(b)$ in the model to determine contributing predictors. The SPSS statistical program, version 17.0 (SPSS, Inc., Chicago, IL, USA), was used throughout this study.

\section{Results and Discussion}

3.1. Ecologic Risk Factors for Dengue Transmission. We attempted to directly relate household-level ecologic determinants with dengue transmission risk. Table 1 reveals the results of the univariate analysis of ecologic risk factors for dengue transmission considering the household-level characteristics. Using $\chi^{2}$ test, 4 out of 11 ecologic variables were found to have a significant association $(P<0.05)$ with frequency of houses having previous history of dengue cases. Four significant variables included ecotope, historical dengue risk area, number of house windows, and presence of screens for house windows. The three variables of ecotope, historical dengue risk area, and presence of screens for house windows were selected for the final multivariate regression while the number of house windows was not entered in the model because it appeared to be of marginal significance. Results of the multivariate analyses are shown in Table 2. In multivariate analysis, these selected determinants were adjusted for their confounding factors by the random effect model. All determinants (the ecotope, historical dengue risk area, and presence of screens for house windows) seemed to have a direct impact on dengue transmission (the LR test, $P<0.05$ ). For the ecotope, three categorical variables (DENPURA, RCDENPURA, and RC) were used to determine their effect on dengue transmission using the commercial ecotope as a reference. Only the ecotope of RCDENPURA remains as a significant predictor for dengue transmission $(\mathrm{aOR}=2.23$, $P=0.009$ ). In terms of dengue risk area, a setting with a high degree of historical dengue transmission indicated OR
(aOR $=2.06, P<0.001)$ significantly higher than an area with a low degree of historical dengue transmission. The last significant variable of presence of screens for house windows showed that houses with window screens had a greater risk (aOR $=1.62, P=0.023)$ than those with no window screens.

Dengue is primarily a mosquito-borne disease found in urban and semiurban settings. The morbidity and mortality attributed to this disease may vary significantly from one place to another on account of different local parameters. In fact, many relevant studies have demonstrated that it is the set of microsocioeconomic, infrastructural, and environmental parameters embedded in communities which appear to be responsible for increased epidemic transmission of dengue virus in particular ecosystem localities [22, 3034]. Ecologic factors investigated in this study are key determinants for dengue transmission risk. In addition, a novel ecosystem concept was created to exhaustively scrutinize the associations between ecotope and the transmission of dengue in the study areas. Of all 4 ecotopes, only the ecotope of RCDENPURA (i.e., where the ecotope is in fact a combination of residential, commercial, and densely populated urban residential areas) exhibited the strongest association with dengue transmission suggesting that the complexity of urban ecosystem may give rise to dengue emergence [13]. To our knowledge, this is the first time that the ecotope, which greatly poses the most risk for dengue occurrence, was determined and characterized.

Historical dengue high risk area also showed a positive association with dengue transmission. This may reaffirm that the area classification based on past history of national surveillance dengue cases has substantial roles in dengue management as well as in providing at-risk areas targeted for the dengue surveillance system and the implementation of dengue control measures. For the variable of having screens for house windows, the presence of house window screens was significantly associated with dengue transmission, compared to the absence of house window screens. Such evidence was consistent with the findings of Chao et al. (2000) [35] while inconsistent with the previous findings of Thammapalo et al. (2012) [36] that households having window screens as a preventive measure showed the reduction of risk in association with human-mosquito contact. In our study, the negative correlation between the presence of house window screens and dengue transmission may result from the cross-sectional survey-where presence of house window screens as an independent variable and houses with a previous history of dengue as dependent variable were measured simultaneously. The existence of many houses that utilize window screens continuously might be due to the perception of dengue and/or due to the health education campaign following dengue outbreaks, whereas the presence of houses with dengue cases was measured after any cases developed within the past year. Accordingly, this finding suggested that the presence of window screens may be dependent upon the particular household's prior dengue risk.

3.2. Sociodemographic Risk Factors for Dengue Transmission. Table 3 shows the results of the univariate analysis of 
TABLE 1: Univariate analysis of the association between ecological factors of households and dengue transmission.

\begin{tabular}{|c|c|c|c|c|}
\hline \multirow{2}{*}{ Categorical variables } & \multirow{2}{*}{$\begin{array}{l}\text { Household number }(\%) \\
\qquad(N=1,200)\end{array}$} & \multicolumn{2}{|c|}{ Houses (\%) with previous history of dengue cases ${ }^{\mathrm{a}}$} & \multirow{2}{*}{$P$ value } \\
\hline & & Yes $(n=164)$ & No $(n=1,036)$ & \\
\hline \multicolumn{5}{|l|}{ Ecotope $^{b}$} \\
\hline Commercial & $200(16.7)$ & $23(14.0)$ & $177(17.1)$ & \multirow{4}{*}{$0.031^{*}$} \\
\hline DENPURA & $200(16.6)$ & $20(12.2)$ & $180(17.4)$ & \\
\hline RCDENPURA & $200(16.7)$ & $39(23.8)$ & $161(15.5)$ & \\
\hline $\mathrm{RC}$ & $600(50.0)$ & $82(50.0)$ & $518(50.0)$ & \\
\hline \multicolumn{5}{|l|}{ Historical dengue risk area } \\
\hline Low & $600(50.0)$ & $57(34.8)$ & $543(52.4)$ & \multirow{2}{*}{$<0.001^{*}$} \\
\hline High & $600(50.0)$ & $107(65.2)$ & $493(47.6)$ & \\
\hline \multicolumn{5}{|l|}{ Number of house floors } \\
\hline One floor & $501(41.8)$ & $70(42.7)$ & $431(41.6)$ & \multirow{2}{*}{0.861} \\
\hline Multifloors & $699(58.2)$ & $94(57.3)$ & $605(58.4)$ & \\
\hline Floor of principal living ${ }^{c}$ & $(N=699)$ & & & \\
\hline First floor & $222(31.8)$ & $34(36.2)$ & $188(31.1)$ & \multirow{2}{*}{0.385} \\
\hline Upper floors & $477(68.2)$ & $60(63.8)$ & 417 (68.9) & \\
\hline \multicolumn{5}{|l|}{ Construction material of house } \\
\hline Concrete/Bricks & $1,035(86.2)$ & $142(86.6)$ & $893(86.2)$ & \multirow{2}{*}{0.990} \\
\hline Wood & $165(13.8)$ & $22(13.4)$ & $143(13.8)$ & \\
\hline \multicolumn{5}{|l|}{ Number of house windows ${ }^{\mathrm{d}}$} \\
\hline $0-9$ & $717(59.8)$ & $86(52.4)$ & $631(60.9)$ & \multirow{2}{*}{$0.049^{*}$} \\
\hline 10 and over & $483(40.2)$ & $78(47.6)$ & $405(39.1)$ & \\
\hline Having screens for house windows ${ }^{e}$ & $(N=1,139)$ & & & \\
\hline No & $407(35.7)$ & $42(27.1)$ & $365(37.1)$ & \multirow{2}{*}{$0.020^{*}$} \\
\hline Yes & $732(64.3)$ & $113(72.9)$ & $619(62.9)$ & \\
\hline \multicolumn{5}{|l|}{ Having a yard/open space } \\
\hline No & $372(31.0)$ & $41(25.0)$ & $331(31.9)$ & \multirow{2}{*}{0.090} \\
\hline Yes & $828(69.0)$ & $123(75.0)$ & $705(68.1)$ & \\
\hline Having bushes in a yard/open space ${ }^{f}$ & $(N=828)$ & & & \\
\hline No & $454(54.8)$ & $72(58.5)$ & $382(54.2)$ & \multirow{2}{*}{0.426} \\
\hline Yes & $374(45.2)$ & $51(41.5)$ & $323(45.8)$ & \\
\hline \multicolumn{5}{|l|}{ Main purpose of house } \\
\hline Residential & $887(73.9)$ & $126(76.8)$ & $761(73.5)$ & \multirow{2}{*}{0.413} \\
\hline Business/restaurant & $313(26.1)$ & $38(23.2)$ & $275(26.5)$ & \\
\hline \multicolumn{5}{|l|}{ House attachment } \\
\hline Attached & $977(81.4)$ & $129(78.7)$ & $848(81.9)$ & \multirow{2}{*}{0.385} \\
\hline Detached & $223(18.6)$ & $35(21.3)$ & $188(18.1)$ & \\
\hline
\end{tabular}

${ }^{a}$ Number of houses with at least one dengue case during the past year.

${ }^{b}$ Urban ecotopes were commercial, densely populated urban residential area-DENPURA, and residential mixed with commercial and DENPURARCDENPURA, whereas semiurban ecotope was residential mixed with commercial-RC.

Of the 1,200 houses, there were ${ }^{\mathrm{c}} 699$ houses that had $\geq 2$ floors; ${ }^{\mathrm{d}} 61$ houses that had no windows; ${ }^{\mathrm{e}} 1,139$ houses that had at least one window; and ${ }^{\mathrm{f}} 828$ houses that had a yard/open space.

* Statistical significance with $\chi^{2}$ test $(P<0.05)$ for two-independent samples.

sociodemographic risk factors related to dengue transmission considering individual-level characteristics. Using $\chi^{2}$ test, 4 out of 22 sociodemographic variables seemed to have a significant association $(P<0.05)$ with frequency of respondents with a history of dengue. Four significant variables were age, highest school degree, residence time in neighborhood, and community effort in environmental management by clean-up campaign, and hence they were selected for further multivariate analysis. Besides these, some variables that either had a significant association at $P$ values of nearly 0.05 or had the potentials of significant phenomena were included in the model. The former variables included residence time in the house and number of household members, while the latter variables constituted movement 
TABLE 2: Multivariate analysis of the association between ecological factors of households and dengue transmission.

\begin{tabular}{|c|c|c|c|c|}
\hline Factors & Crude OR $(95 \% \mathrm{CI})$ & adj. OR (95\%CI) & $P$ value* & $P$ value** \\
\hline \multicolumn{5}{|l|}{ Ecotope } \\
\hline Commercial & 1 & & & $0.032^{* *}$ \\
\hline DENPURA & $0.90(0.48,1.72)$ & $1.15(0.58,2.25)$ & 0.691 & \\
\hline RCDENPURA & $1.81(1.02,3.21)$ & $2.23(1.22,4.07)$ & $0.009^{*}$ & \\
\hline $\mathrm{RC}$ & $1.19(0.72,1.97)$ & $1.23(0.74,2.05)$ & 0.423 & \\
\hline \multicolumn{5}{|c|}{ Historical dengue risk area } \\
\hline Low & 1 & & & \\
\hline High & $2.16(1.51,3.09)$ & $2.06(1.43,2.95)$ & $<0.001^{*}$ & $<0.001^{* *}$ \\
\hline \multicolumn{5}{|c|}{ Having screens for house windows } \\
\hline No & 1 & & & \\
\hline Yes & $1.59(1.09,2.31)$ & $1.62(1.07,2.46)$ & $0.023^{*}$ & $0.02^{* *}$ \\
\hline
\end{tabular}

OR: odds ratios. CI: confidence interval. Statistical significance $(P<0.05)$ using the Wald's test* and the likelihood-ratio test.**

during last 3 months and knowledge about dengue and its vectors. The sociodemographic multivariate analyses revealed findings of the association between 8 individual determinants and dengue transmission (Table 4).

Among all determinants tested, 5 of them which included age, highest school degree, residence time in neighborhood, number of household members, and community effort in environmental management by clean-up campaign posed significant risk for dengue transmission (the LR test, $P<$ $0.05)$. Respondents aged $>45$ years showed significant risk for dengue transmission $(\mathrm{aOR}=3.24, P=0.003)$ compared to those aged $\leq 45$ years. With regards to highest school degree, individuals with middle and higher degrees were twice as likely to get dengue infection $(\mathrm{aOR}=2.33, P=0.013)$ compared to those with elementary and lower degrees. In contrast to the univariate analysis, household members $>4$ persons were likely to experience a greater risk $(\mathrm{aOR}=2.01$, $P=0.02$ ) of dengue transmission than those with $\leq 4$ persons. The last significant predictor was the presence of a community effort in environmental management by cleanup campaign, which was statistically associated with dengue transmission $(\mathrm{aOR}=1.91, P=0.035)$ compared to the absence of community effort.

Sociodemographic factors are commonly targeted for disease prevention and control and underpin successful public health programs [37]. Although there have been promising indications in the literature, some parameters are not well understood in the case of dengue. Risk factors related to dengue transmission are very much influenced by individual and environmental determinants. In this study, individual-level sociodemographic predictors and confounders adjusted for dengue transmission were analyzed through a series of logistic regression models. Older age was associated with higher risk in the area and was in agreement with an earlier study [38]. Furthermore, several other studies have shown that increasing age was significantly associated with dengue transmission [39-41]. Persons who earned secondary and higher degrees of education had a higher risk than those who earned elementary and lower degrees. Regardless of the birth place, this possibly relates to the shorter residence time in neighborhood of respondents that possessed greater risk for dengue transmission compared to the longer residence time. The explanation of such phenomena is that persons who have a high level of schooling may have more chance to get skilled careers. Accordingly, these career opportunities lead to the movement of people seeking jobs far away from their hometown or community, which increases their risk of getting a dengue viral infection from the place where they have moved to work. If infected, these persons could then transmit the dengue virus to their family members and/or others around their homes. Human movement significantly favoring the transmission of dengue correlates well with recent studies [42-44] that have shown this factor to be a major contributor to the acceleration of dengue virus dispersal (and hence disease distribution in space and time), especially between urban/semiurban and rural communities. Human migration allows multiple exposure to Aedes aegypti bites among migratory people; in other words, mobile persons have a greater chance of coming into close contact with various bites at multiple locations, especially in public spaces. However, our study did not show a positive association between movements during the previous 3 months and dengue transmission. Larger numbers of household members were more at risk for significant exposure to dengue transmission compared to smaller ones. This finding was supported by the previous study [45] that people gathering with daily activities in a house created the exposure frequency of the bites of denguevirus infected Aedes mosquitoes.

We attempted to evaluate the relative magnitude of knowledge, attitude, and practice of respondents on reducing dengue risk. The knowledge about dengue and its vectors and the attitude about vector control demonstrated no significant association with dengue transmission. For the practice regarding vector control, only the community effort in environmental management by cleaning campaign had a significant effect both in univariate and multivariate analyses. As for the presence of house window screens, this factor was associated with an increase in dengue transmission. Possible explanations are that dengue control efforts by either household members or community participation have generally been performed following the good perception 
TABLE 3: Univariate analysis of the association between sociodemographic factors of respondents and dengue transmission.

\begin{tabular}{|c|c|c|c|c|}
\hline \multirow{2}{*}{ Categorical variables } & \multirow{2}{*}{$\begin{array}{l}\text { Respondent number }(\%) \\
\qquad(N=1,200)\end{array}$} & \multicolumn{2}{|c|}{ Respondents (\%) with dengue history } & \multirow{2}{*}{$P$ value } \\
\hline & & Yes $(n=59)$ & No $(n=1,141)$ & \\
\hline \multicolumn{5}{|l|}{ Age (years) } \\
\hline$\leq 45$ & $580(48.3)$ & $10(16.9)$ & $570(50)$ & \multirow{2}{*}{$<0.001^{*}$} \\
\hline$>45$ & $620(51.7)$ & $49(83.1)$ & $571(50)$ & \\
\hline \multicolumn{5}{|l|}{ Highest school degree } \\
\hline Elementary and lower & $616(51.3)$ & $14(23.7)$ & $602(52.8)$ & \multirow{2}{*}{$<0.001^{*}$} \\
\hline Secondary and higher & $584(48.7)$ & $45(76.3)$ & $539(47.2)$ & \\
\hline \multicolumn{5}{|l|}{ Occupation } \\
\hline Unemployed & $333(27.8)$ & $12(20.3)$ & $321(28.1)$ & \multirow{3}{*}{0.376} \\
\hline Unskilled worker & $635(52.9)$ & $33(55.9)$ & $602(52.8)$ & \\
\hline Skilled worker & $232(19.3)$ & $14(23.7)$ & $218(19.1)$ & \\
\hline \multicolumn{5}{|c|}{ Movement during last 3 months } \\
\hline Yes & $79(6.6)$ & $7(11.9)$ & $72(6.3)$ & \multirow{2}{*}{0.159} \\
\hline No & $1,121(93.4)$ & $52(88.1)$ & $1,069(93.7)$ & \\
\hline \multicolumn{5}{|c|}{ Residence time in house (years) } \\
\hline$>15$ & $409(34.1)$ & $13(22.0)$ & $396(34.7)$ & \multirow{2}{*}{0.063} \\
\hline$\leq 15$ & $791(65.9)$ & $46(78.0)$ & $745(65.3)$ & \\
\hline \multicolumn{5}{|c|}{ Residence time in neighborhood (years) } \\
\hline$>15$ & $524(43.7)$ & $14(23.7)$ & $510(44.7)$ & \multirow{2}{*}{$0.002^{*}$} \\
\hline$\leq 15$ & $676(56.3)$ & $45(76.3)$ & $631(55.3)$ & \\
\hline \multicolumn{5}{|c|}{ Number of household members (persons) } \\
\hline $1-4$ & $914(76.2)$ & $39(66.1)$ & $875(76.7)$ & \multirow{2}{*}{0.088} \\
\hline$>4$ & $286(23.8)$ & $20(33.9)$ & $266(23.3)$ & \\
\hline \multicolumn{5}{|c|}{ Average family income (Baht) } \\
\hline$\leq 5,000$ & $656(54.7)$ & $26(44.1)$ & $630(55.2)$ & \multirow{2}{*}{0.123} \\
\hline$>5,000$ & $544(45.3)$ & $33(55.9)$ & $511(44.8)$ & \\
\hline \multicolumn{5}{|c|}{ Knowledge about dengue and its vectors } \\
\hline Low & $147(12.2)$ & $11(18.6)$ & $136(11.9)$ & \multirow{2}{*}{0.183} \\
\hline High & $1,053(87.8)$ & $48(81.4)$ & $1,005(88.1)$ & \\
\hline \multicolumn{5}{|c|}{ Attitude about vector control } \\
\hline Gender role & & & & \\
\hline Low/fair & $688(57.3)$ & $33(55.9)$ & $655(57.4)$ & 0.930 \\
\hline High & $512(42.7)$ & $26(44.1)$ & $486(42.6)$ & 0.350 \\
\hline Family role & & & & \\
\hline Low & $506(42.2)$ & $28(47.5)$ & $478(41.9)$ & 0.478 \\
\hline Fair & $694(57.8)$ & $31(52.5)$ & $663(58.1)$ & \\
\hline Government role & & & & \\
\hline Low/fair & $506(42.2)$ & $28(47.5)$ & $478(41.9)$ & 0.478 \\
\hline High & $694(57.8)$ & $31(52.5)$ & $663(58.1)$ & $0.4 / 0$ \\
\hline Household water storage & & & & \\
\hline Yes & $1,122(93.5)$ & $55(93.2)$ & $1,067(93.5)$ & 0.856 \\
\hline No & $78(6.5)$ & $4(6.8)$ & $74(6.5)$ & \\
\hline $\begin{array}{l}\text { Household practice to red } \\
\text { mosquitoes }{ }^{\text {a }}\end{array}$ & & & & \\
\hline Chemical control & & & & \\
\hline Low & $848(70.7)$ & $48(81.4)$ & $800(70.1)$ & 0.089 \\
\hline High & $352(29.3)$ & $11(18.6)$ & $341(29.9)$ & \\
\hline
\end{tabular}


TABle 3: Continued.

\begin{tabular}{|c|c|c|c|c|}
\hline \multirow{2}{*}{ Categorical variables } & \multirow{2}{*}{$\begin{array}{l}\text { Respondent number }(\%) \\
\qquad(N=1,200)\end{array}$} & \multicolumn{2}{|c|}{ Respondents (\%) with dengue history } & \multirow{2}{*}{$P$ value } \\
\hline & & Yes $(n=59)$ & No $(n=1,141)$ & \\
\hline \multicolumn{5}{|l|}{ Physical control } \\
\hline Low & $667(55.6)$ & $38(64.4)$ & $629(55.1)$ & \multirow{2}{*}{0.206} \\
\hline High & $533(44.4)$ & $21(35.6)$ & $512(44.9)$ & \\
\hline \multicolumn{5}{|l|}{ Biological control } \\
\hline Yes & $273(22.8)$ & $16(27.1)$ & $257(22.5)$ & \multirow{2}{*}{0.508} \\
\hline No & $927(77.2)$ & $43(72.9)$ & $884(77.5)$ & \\
\hline \multicolumn{5}{|c|}{$\begin{array}{l}\text { Household practices to prevent Aedes breeding } \\
\text { place }^{\text {a }}\end{array}$} \\
\hline \multicolumn{5}{|c|}{ Chemical control } \\
\hline Yes & $993(82.8)$ & $47(79.7)$ & $946(82.9)$ & \multirow{2}{*}{0.640} \\
\hline No & $207(17.2)$ & $12(20.3)$ & $195(17.1)$ & \\
\hline \multicolumn{5}{|l|}{ Physical control } \\
\hline Low & $270(22.5)$ & $14(23.7)$ & $256(22.4)$ & \multirow{2}{*}{0.943} \\
\hline High & $930(77.5)$ & $45(76.3)$ & $885(77.6)$ & \\
\hline \multicolumn{5}{|l|}{ Biological control } \\
\hline Yes & $676(56.3)$ & $33(55.9)$ & $643(56.4)$ & \multirow{2}{*}{1.000} \\
\hline No & $524(43.7)$ & $26(44.1)$ & $498(43.6)$ & \\
\hline \multicolumn{5}{|c|}{ Last time visited by health personnel } \\
\hline Yes (if any time) & $856(71.3)$ & $39(66.1)$ & $817(71.6)$ & \multirow{2}{*}{0.445} \\
\hline No/don't remember & $344(28.7)$ & $20(33.9)$ & $324(28.4)$ & \\
\hline \multicolumn{5}{|c|}{ Receiving dengue control support/materials } \\
\hline Yes & $934(77.8)$ & $41(69.5)$ & $893(78.3)$ & \multirow{2}{*}{0.155} \\
\hline No & $266(22.2)$ & $18(30.5)$ & $248(21.7)$ & \\
\hline \multirow{2}{*}{\multicolumn{5}{|c|}{$\begin{array}{l}\text { Community effort in environmental } \\
\text { management by clean-up campaign }\end{array}$}} \\
\hline & & & & \\
\hline Yes & $513(42.8)$ & $16(27.1)$ & $497(43.6)$ & \multirow{2}{*}{$0.019^{*}$} \\
\hline No/don't know & $687(57.2)$ & $43(72.9)$ & $644(56.4)$ & \\
\hline
\end{tabular}

${ }^{a}$ Household activities of controlling dengue vector and their assessment were described in the text.

* Statistical significance using $\chi^{2}$ test $(P<0.05)$ for two-independent samples.

and/or especially during/after dengue outbreaks. In Thailand, dengue prevention and control efforts such as eliminating Aedes breeding sites either by individual households or by community participation, personal protection, window screens, and fogging have been intensively applied following the dengue experiences or dengue outbreaks.

\section{Conclusions}

An integrated analysis of the ecosocial determinants for dengue transmission risk in this study provides meaningful implications and hence it merits the improvement of understanding dynamics of dengue transmission in complex epidemiological settings. First, the ecological analysis model indicated enhanced risk in the RCDENPURA ecotope (i.e., a combination of residential, commercial, and densely populated urban residential areas), in the historical high dengue risk area and in households where screens for windows were present. The ecotope of RCDENPURA and the historical high dengue risk area appear to be very good predictors for dengue incidences. This suggests that dengue control programs could successfully focus on these determinants embedded in the urban ecosystem or elsewhere, especially during an economic crisis and/or when there is a small budget for such programs. Second, the sociological analysis model also revealed plausible significant determinants of older age, higher level of schooling, residence time in the neighborhood, larger household size, and community effort in environmental management by clean-up campaign. Regarding the dynamics of sociodemographic contexts and modern lifestyles, these sociodemographic predictors will significantly help us to understand the processes of dengue transmission dynamics and to implement dengue prevention and control programs effectively and efficiently. Lastly, variances of pertinently ecological and social determinants should be taken into consideration when deliberately formulating local dengue prevention/control programs to gain benefits for both communities and government health practitioners. Meanwhile, these present findings also provide principal grounds for ecosystem and sociodemographic 
TABLE 4: Multivariate analysis of the association between sociodemographic factors of respondents and dengue transmission.

\begin{tabular}{|c|c|c|c|c|}
\hline Factors & Crude OR (95\%CI) & adj. OR (95\%CI) & $P$ value* & $P$ value** \\
\hline \multicolumn{5}{|l|}{ Age (years) } \\
\hline$\leq 45$ & 1 & & & \\
\hline$>45$ & $4.89(2.45,9.75)$ & $3.24(1.51,6.97)$ & $0.003^{*}$ & $0.001^{* *}$ \\
\hline \multicolumn{5}{|l|}{ Highest school degree } \\
\hline Elementary and lower & 1 & & & \\
\hline Secondary and higher & $3.59(1.95,6.61)$ & $2.33(1.19,4.55)$ & $0.013^{*}$ & $0.009^{* *}$ \\
\hline \multicolumn{5}{|c|}{ Movement during last 3 months } \\
\hline No & 1 & & & \\
\hline Yes & $3.59(0.88,6.61)$ & $2.33(0.91,4.55)$ & 0.080 & 0.103 \\
\hline \multicolumn{5}{|c|}{ Residence time in house (years) } \\
\hline$>15$ & 1 & & & \\
\hline$\leq 15$ & $1.88(1.00,3.52)$ & $0.21(0.03,1.35)$ & 0.100 & 0.054 \\
\hline \multicolumn{5}{|c|}{ Residence time in neighborhood (years) } \\
\hline$>15$ & 1 & & & \\
\hline$\leq 15$ & $2.6(1.41,4.79)$ & $6.19(1.03,37.26)$ & $0.047^{*}$ & $0.011^{* *}$ \\
\hline \multicolumn{5}{|c|}{ Number of household members (persons) } \\
\hline $1-4$ & 1 & & & \\
\hline$>4$ & $1.69(0.97,2.94)$ & $2.01(1.12,3.6)$ & $0.020^{*}$ & $0.024^{* *}$ \\
\hline \multicolumn{5}{|c|}{ Knowledge about dengue and its vectors } \\
\hline High & 1 & & & \\
\hline Low & $1.69(0.86,3.34)$ & $1.9(0.93,3.88)$ & 0.080 & 0.096 \\
\hline \multicolumn{5}{|c|}{$\begin{array}{l}\text { Community effort in environmental } \\
\text { management by clean-up campaign }\end{array}$} \\
\hline No/don't know & 1 & & & \\
\hline Yes & $2.07(1.15,3.73)$ & $1.91(1.05,3.49)$ & $0.035^{*}$ & $0.029 * *$ \\
\hline
\end{tabular}

OR: odds ratios. CI: confidence interval. Statistical significance $(P<0.05)$ using the Wald's test* and the likelihood-ratio test.**

approaches to dengue transmission for researchers in academic institutions.

\section{Acknowledgments}

This study was financially supported by the WHO/TDR/ EBS-IDRC (A60618) and the Mahidol University Research Program Grant (MU39/53). The authors would like to sincerely thank Dr. Johannes Sommerfeld and Dr. Bruce A. Wilcox for their outstanding comments; Dr. Apiradee Lim for her excellent advice in statistical analysis; Mr. David Blyler for his professional proofreading and English language editing. The authors are grateful to respondents in the four study areas for kindly providing information and allowing the survey of their houses. The ethical clearance of this study was reviewed and approved by the Institution Review Board of Mahidol University in Thailand (COA. no. MU-IRB 2009/162.2307).

\section{References}

[1] D. J. Gubler, "Resurgent vector-borne diseases as a global health problem," Emerging Infectious Diseases, vol. 4, no. 3, pp. 442-450, 1998.

[2] D. J. Gubler, "Epidemic dengue/dengue hemorrhagic fever as a public health, social and economic problem in the 21 st century," Trends in Microbiology, vol. 10, no. 2, pp. 100-103, 2002.

[3] M. G. Guzman and G. Kouri, "Dengue: an update," The Lancet Infectious Diseases, vol. 2, pp. 33-42, 2002.

[4] P. Daszak, "Emerging infectious diseases and the socioecological dimension," EcoHealth, vol. 2, no. 4, pp. 239-240, 2005.

[5] B. A. Wilcox and R. R. Colwell, "Emerging and reemerging infectious diseases: biocomplexity as an interdisciplinary paradigm," EcoHealth, vol. 2, no. 4, pp. 244-257, 2005.

[6] WHO, Dengue: Guidelines for Diagnosis, Treatment, Prevention and Control, World Health Organization, Paris, France, 2009.

[7] G. P. Kouri, M. G. Guzman, J. R. Bravo, and C. Triana, "Dengue haemorrhagic fever/dengue shock syndrome: lessons from the Cuban epidemic, 1981," Bulletin of the World Health Organization, vol. 67, no. 4, pp. 375-380, 1989.

[8] B. T. Tan, "Control of dengue fever/dengue haemorrhagic fever in Singapore,” Dengue Bulletin, vol. 21, pp. 30-34, 1997.

[9] M. I. Brightmer and M. G. Fantato, "Human and environmental factors in the increasing incidence of dengue fever: a case study form Venezuela," GeoJournal, vol. 44, no. 2, pp. 103-109, 1998.

[10] P. Butraporn, W. Saelim, and P. Sitaputra, "Establishment of an environmental master team to control dengue haemorrhagic fever by local wisdom in Thailand," Dengue Bulletin, vol. 23, pp. 1-4, 1999.

[11] B. Kay and V. S. Nam, "New strategy against Aedes aegypti in Vietnam,” The Lancet, vol. 365, no. 9459, pp. 613-617, 2005. 
[12] P. Kittayapong, S. Yoksan, U. Chansang, C. Chansang, and A. Bhumiratana, "Suppression of dengue transmission by application of integrated vector control strategies at seropositive GIS-based foci," American Journal of Tropical Medicine and Hygiene, vol. 78, no. 1, pp. 70-76, 2008.

[13] P. Horwitz and B. A. Wilcox, "Parasites, ecosystems and sustainability: an ecological and complex systems perspective," International Journal for Parasitology, vol. 35, no. 7, pp. 725732, 2005.

[14] B. A. Wilcox and D. J. Gubler, "Disease ecology and the global emergence of zoonotic pathogens," Environmental Health and Preventive Medicine, vol. 10, no. 5, pp. 263-272, 2005.

[15] D. Despommier, B. R. Ellis, and B. A. Wilcox, "The role of ecotones in emerging infectious diseases," EcoHealth, vol. 3, no. 4, pp. 281-289, 2006.

[16] M. Bonet, J. M. Spiegel, A. M. Ibarra, G. Kouri, A. Pintre Lic, and A. Yassi, "An integrated ecosystem approach for sustainable prevention and control of dengue in Central Havana," International Journal of Occupational and Environmental Health, vol. 13, no. 2, pp. 188-194, 2007.

[17] P. C. Wu, J. G. Lay, H. R. Guo, C. Y. Lin, S. C. Lung, and H. J. Su, "Higher temperature and urbanization affect the spatial patterns of dengue fever transmission in subtropical Taiwan," Science of the Total Environment, vol. 407, no. 7, pp. 22242233, 2009.

[18] K. C. Castillo, B. Körbl, A. Stewart, J. F. Gonzalez, and F. Ponce, "Application of spatial analysis to the examination of dengue fever in Guayaquil, Ecuador," Procedia Environmental Sciences, vol. 7, pp. 188-193, 2011.

[19] H. M. Khormi and L. Kumar, "Modeling dengue fever risk based on socioeconomic parameters, nationality and age groups: GIS and remote sensing based case study," Science of the Total Environment, vol. 409, no. 22, pp. 4713-4719, 2011.

[20] Y. H. Hsueh, J. Lee, and L. Beltz, "Spatio-temporal patterns of dengue fever cases in Kaoshiung City, Taiwan, 2003-2008," Applied Geography, vol. 34, pp. 587-594, 2012.

[21] R. A. Erickson, S. M. Presley, L. J. S. Allen, K. R. Long, and S. B. Cox, "A dengue model with a dynamic Aedes albopictus vector population," Ecological Modelling, vol. 221, no. 24, pp. 2899-2908, 2010.

[22] J. S. Koopman and I. M. Longini Jr., "The ecological effects of individual exposures and nonlinear disease dynamics in populations," American Journal of Public Health, vol. 84, no. 5, pp. 836-842, 1994.

[23] J. Spiegel, S. Bennett, L. Hattersley et al., "Barriers and bridges to prevention and control of dengue: the need for a socialecological approach," EcoHealth, vol. 2, no. 4, pp. 273-290, 2005.

[24] B. R. Ellis and B. A. Wilcox, "The ecological dimensions of vector-borne disease research and control," Cadernos de Saude Publica, vol. 25, no. 1, supplement, pp. S155-S167, 2009.

[25] R. Suárez, C. González, G. Carrasquilla, and J. Quintero, "An ecosystem perspective in the socio-cultural evaluation of dengue in two Colombian towns," Cadernos de Saude Publica, vol. 25, no. 1, supplement, pp. S104-S114, 2009.

[26] N. Arunachalam, S. Tana, F. Espino et al., "Eco-bio-social determinants of dengue vector breeding: a multicountry study in urban and periurban Asia," Bulletin of the World Health Organization, vol. 88, no. 3, pp. 173-184, 2010.

[27] H. Padmanabha, E. Soto, M. Mosquera, C. C. Lord, and L. P. Lounibos, "Ecological links between water storage behaviors and Aedes aegypti production: implications for dengue vector control in variable climates," EcoHealth, vol. 7, no. 1, pp. 7890, 2010.
[28] Bureau of Epidemiology, Department of Disease Control, and Ministry of Public Health, "Dengue fever," June 2007, http://www.boe.moph.go.th/.

[29] Chachoengsao Provincial Public Health Office and Information System for Health Management, June2007, http:// data.cco.moph.go.th/provis/main/index.php.

[30] J. S. Koopman, D. R. Prevots, M. A. V. Marin et al., "Determinants and predictors of dengue infection in Mexico," American Journal of Epidemiology, vol. 133, no. 11, pp. 11681178, 1991.

[31] S. J. Schrag and P. Wiener, "Emerging infectious disease: what are the relative roles of ecology and evolution?" Trends in Ecology and Evolution, vol. 10, no. 8, pp. 319-324, 1995.

[32] P. Reiter, "Climate change and mosquito-borne disease," Environmental Health Perspectives, vol. 109, no. 1, supplement, pp. 141-161, 2001.

[33] A. T. Peterson, C. Martínez-Campos, Y. Nakazawa, and E. Martínez-Meyer, "Time-specific ecological niche modeling predicts spatial dynamics of vector insects and human dengue cases," Transactions of the Royal Society of Tropical Medicine and Hygiene, vol. 99, no. 9, pp. 647-655, 2005.

[34] S. Carver, A. Bestall, A. Jardine, and R. S. Ostfeld, "Influence of hosts on the ecology of arboviral transmission: potential mechanisms influencing dengue, Murray Valley encephalitis, and Ross River virus in Australia," Vector-Borne and Zoonotic Diseases, vol. 9, no. 1, pp. 51-64, 2009.

[35] D. Y. Chao, Y. C. Lu, T. H. Lin, P. Y. Chu, S. J. Chang, J. H. Huang et al., "Predisposing factors of dengue cases by random effect model in the largest dengue haemorrhagic fever epidemic in Taiwan in 1998," Dengue: Bulletins, vol. 24, pp. 8 $12,2000$.

[36] S. Thammapalo, S. Meksawi, and V. Chongsuvivatwong, "Effectiveness of space spraying on the transmission of dengue/dengue hemorrhagic fever (DF/DHF) in an urban area of southern Thailand," Journal of Tropical Medicine, vol. 2012, Article ID 652564, 7 pages, 2012.

[37] A. Mondini and F. Chiaravalloti-Neto, "Spatial correlation of incidence of dengue with socioeconomic, demographic and environmental variables in a Brazilian city," Science of the Total Environment, vol. 393, no. 2-3, pp. 241-248, 2008.

[38] C. Braga, C. F. Luna, C. M. T. Martelli et al., "Seroprevalence and risk factors for dengue infection in socio-economically distinct areas of Recife, Brazil," Acta Tropica, vol. 113, no. 3, pp. 234-240, 2010.

[39] L. Rodriguez-Figueroa, J. G. Rigau-Perez, E. L. Suarez, and P. Reiter, "Risk factors for dengue infection during an outbreak in Yanes, Puerto Rico in 1991," American Journal of Tropical Medicine and Hygiene, vol. 52, no. 6, pp. 496-502, 1995.

[40] E. E. Ooi, T. J. Hart, H. C. Tan, and S. H. Chan, "Dengue seroepidemiology in Singapore," The Lancet, vol. 357, no. 9257, pp. 685-686, 2001.

[41] D. A. T. Cummings, S. Iamsirithaworn, J. T. Lessler et al., "The impact of the demographic transition on dengue in Thailand: insights from a statistical analysis and mathematical modeling," PLoS Medicine, vol. 6, no. 9, Article ID e1000139, 2009.

[42] N. A. Maidana and H. M. Yang, "Describing the geographic spread of dengue disease by traveling waves," Mathematical Biosciences, vol. 215, no. 1, pp. 64-77, 2008.

[43] B. Adams and D. D. Kapan, "Man bites mosquito: understanding the contribution of human movement to vector-borne disease dynamics," PLoS ONE, vol. 4, no. 8, Article ID e6763, 2009. 
[44] S. T. Stoddard, A. C. Morrison, G. M. Vazquez-Prokopec et al., "The role of human movement in the transmission of vectorborne pathogens," PLoS Neglected Tropical Diseases, vol. 3, no. 7, article e481, 2009.

[45] M. E. J. Woolhouse, C. Dye, J. F. Etard et al., "Heterogeneities in the transmission of infectious agents: implications for the design of control programs," Proceedings of the National Academy of Sciences of the United States of America, vol. 94, no. 1, pp. 338-342, 1997. 


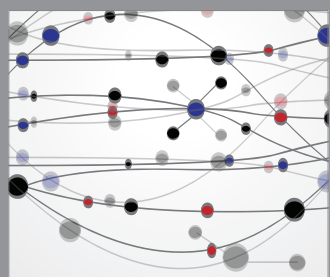

The Scientific World Journal
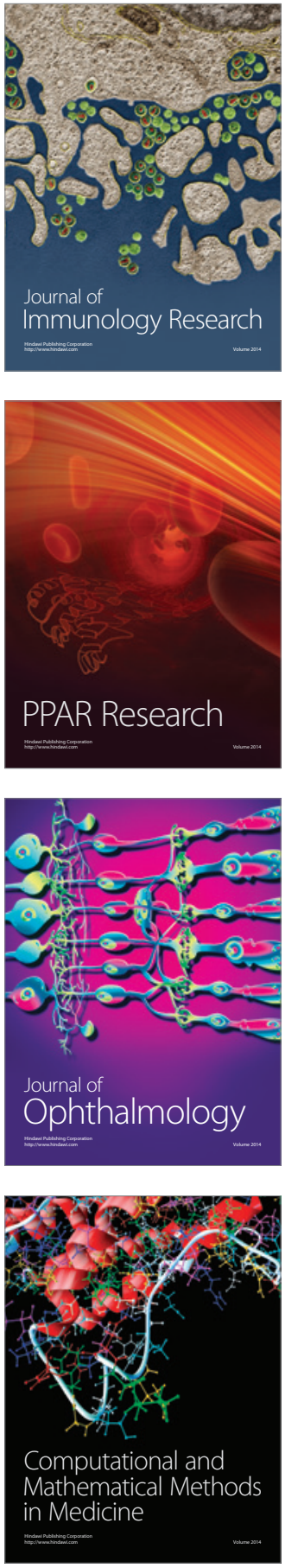

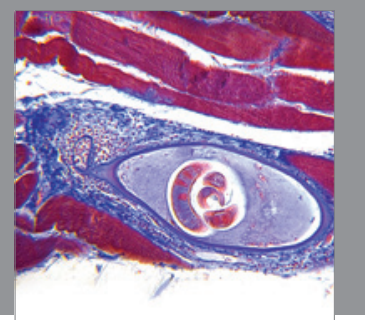

Gastroenterology

Research and Practice
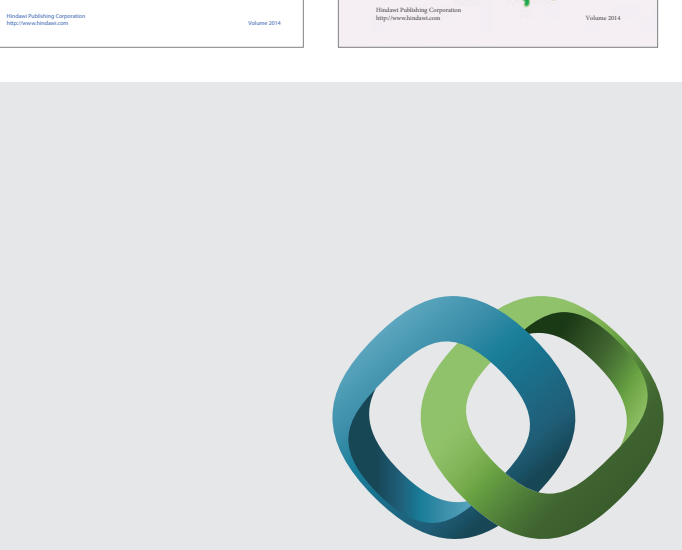

\section{Hindawi}

Submit your manuscripts at

http://www.hindawi.com
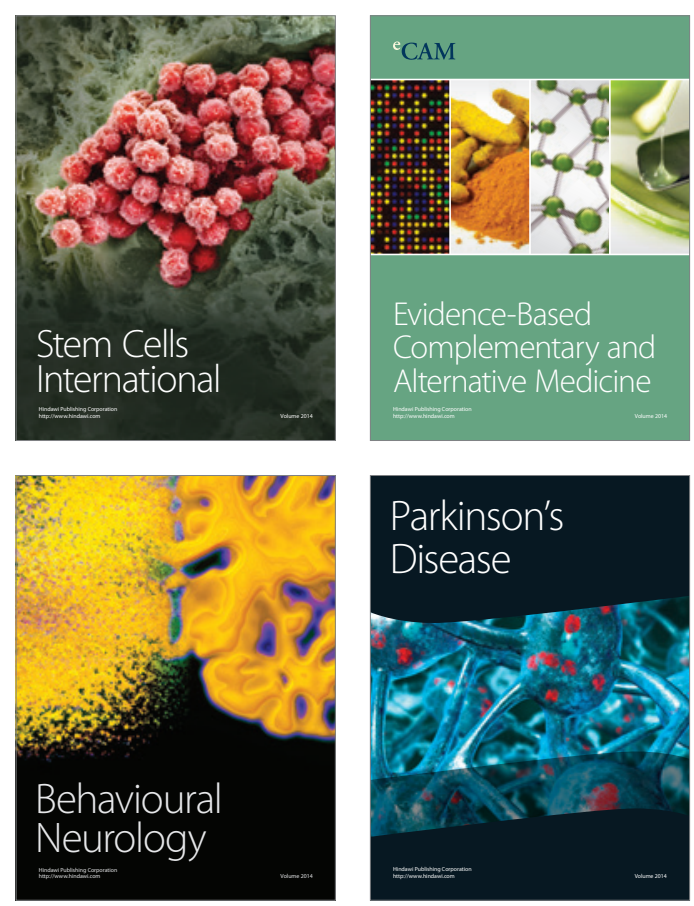

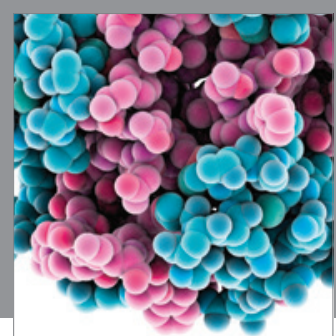

Journal of
Diabetes Research

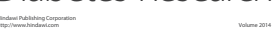

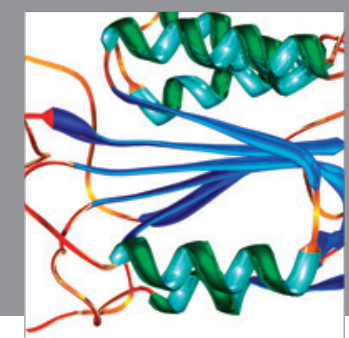

Disease Markers
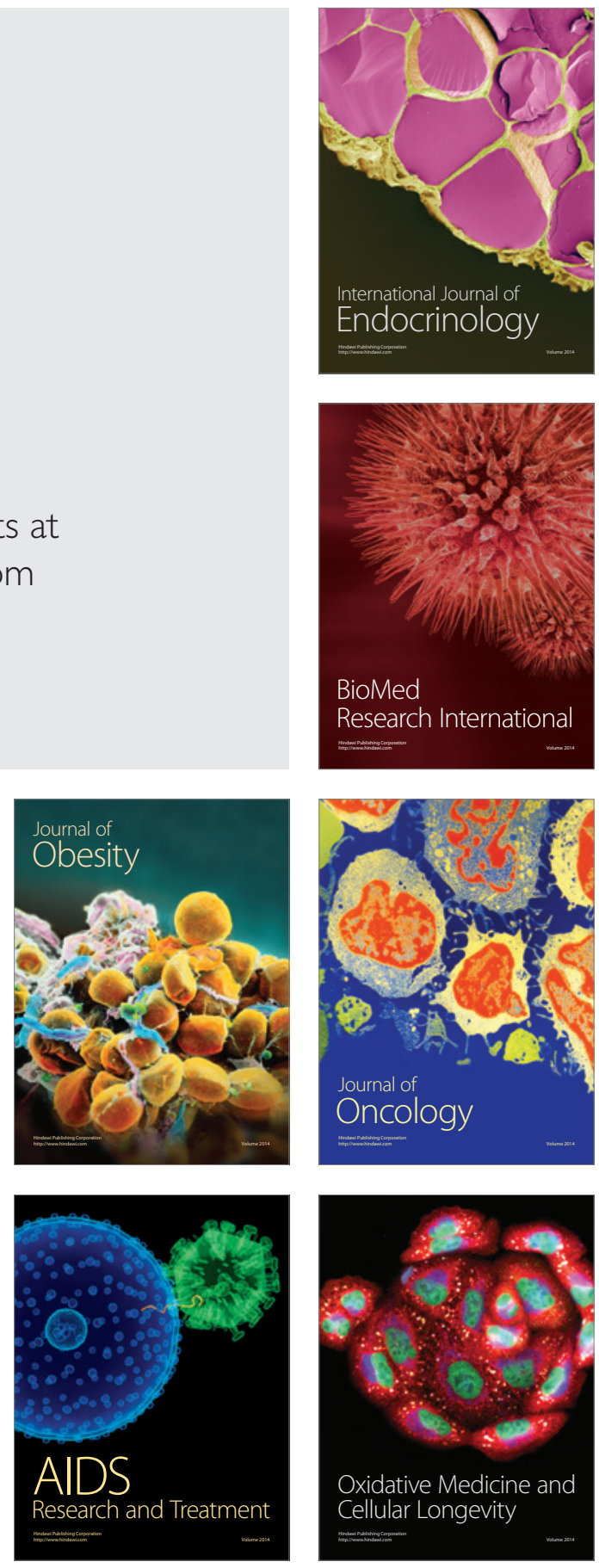